\title{
Neuroendocrine tumors of the gastrointestinal tract and pancreas: Is it also a challenge for pediatricians?
}

\author{
Andrzej Stawarski ${ }^{\mathrm{A}, \mathrm{E}, \mathrm{F}}$, Paweł Maleika ${ }^{\mathrm{B}-\mathrm{D}}$ \\ Department and Clinic of Pediatrics, Gastroenterology and Nutrition, Wroclaw Medical University, Poland \\ A - research concept and design; B - collection and/or assembly of data; $C$ - data analysis and interpretation; \\ $D$ - writing the article; $E$ - critical revision of the article; $F$ - final approval of the article
}

Address for correspondence

Paweł Maleika

E-mail: pawel.maleika@umed.wroc.pl

Funding sources

None declared

Conflict of interest

None declared

Received on June 17, 2019

Reviewed on July 4, 2019

Accepted on August 18, 2019

Published online on February 24, 2020

\begin{abstract}
Neuroendocrine tumors (NET) of the gastrointestinal tract and pancreas are extremely rare in the pediatric population and limited data is available. In most cases, NET of the gastrointestinal tract in children are located in the appendix. Pancreatic NET are a small but partially distinct group of the gastrointestinal neuroendocrine neoplasms. The most common in this group are insulinomas; however, in some research, the gastrinoma type neoplasms are perceived to be most common in children. This study reviews the typical clinical presentation, appropriate diagnostics, staging, and treatment of these uncommon neoplasms. It is important to know the epidemiology and symptomatology in this age group despite the fact that the majority of physicians treating the youngest patients will never have to deal with it. This will facilitate an early diagnosis in case of symptoms that may suggest neuroendocrine cancer. It appears necessary to create harmonized recommendations regarding the diagnosis, treatment and post-treatment follow-up for pediatric patients.
\end{abstract}

Key words: neuroendocrine tumors, pediatric, gastroenterology

Cite as

Stawarski A, Maleika P. Neuroendocrine tumors of the gas-

trointestinal tract and pancreas: Is it also a challenge for pediatricians? Adv Clin Exp Med. 2020;29(2):265-270.

doi:10.17219/acem/111806

DOI

10.17219/acem/111806

Copyright

Copyright by Author(s)

This is an article distributed under the terms of the

Creative Commons Attribution 3.0 Unported (CC BY 3.0)

(https://creativecommons.org/licenses/by/3.0/) 


\section{Introduction}

Neuroendocrine neoplasms of the gastrointestinal tract and pancreas are a rare, heterogeneous group of neoplasms developing from the neuroendocrine system cells. Recent studies have shown that they derive from the local, multipotential progenitor cells that differentiate into neuroendocrine phenotype cells, rather than, as suspected before, from the migrating nerve crest cells. ${ }^{1,2}$ This group includes tumors that produce hormones or biogenic amines, as well as the ones not producing such substances or not producing them in sufficient quantities to demonstrate clinical signs; such tumors are referred to as hormonally inactive. Neuroendocrine tumors (NET) are a major challenge for pediatricians, as they are very rare in children and data on symptomatology and clinical course in the pediatric population is limited.

\section{Classification}

Several different classifications have been proposed since this group of tumors was described about 100 years ago. Currently, the World Health Organization (WHO) guideline-based division, introduced in 2017, is being applied and it takes into account the histological tumor grade (G trait), pathomorphological (tumor-nodule-metastasis (TNM) system) and clinical staging. The most important parameter of a tumor is its histological maturity, evaluated using the proliferative index Ki-67 and its mitotic count. This has enabled the creation of 2 categories: the welldifferentiated tumors with proliferative index Ki-67 < 20\% and the poorly differentiated tumors with proliferative index Ki-67 > 20\%. In 2017, the latter category included a subcategory of large and small cell neuroendocrine carcinomas (NEC) characterized by an exceptionally aggressive course and a subcategory of the well-differentiated neoplasms with Ki-67 proliferative index above 20\% (NET G3) (Table 1$).{ }^{3}$ Further treatment is determined by the category the tumor is assigned to.

\section{Epidemiology}

The incidence of NET in adults is estimated at about 5 cases per 100,000 people. ${ }^{4}$ In children, the exact data is not known. Several studies assessing their incidence in children and young adults are available and they present values ranging from 1.14 per $1,000,000^{5}$ to 2.8 per $1,000,000$ people. ${ }^{6}$ Neuroendocrine neoplasms of the gastrointestinal tract and the pancreas are the most common among all the NET in children and take the top position among all gastrointestinal neoplasms in pediatric patients. ${ }^{7,8}$

In adults, NET develop most frequently in the rectum or small intestine, ${ }^{4}$ whilst in children they are most commonly located in the appendix. According to various studies, the average age for disease onset is $12-15$ years. ${ }^{9-12}$ The NET are more common in girls.

Pancreatic NET are a small but partially distinct group of gastrointestinal neuroendocrine neoplasms. The literature provides a very limited amount of data concerning their prevalence in the pediatric population. One study, which analyzed the cases of insulinoma within 60 years, demonstrated that pediatric patients (over 10 years of age) accounted for $4.9 \%$ of all cases. No gender predilection has been shown. ${ }^{13}$ Insulinoma-type tumors are believed to be the most common in children, whilst in some research, the gastrinoma-type tumors are perceived to be most common in this group. A higher risk of pancreatic NET is observed in genetic syndromes such as multiple endocrine neoplasia type 1 (MEN1), von Hippel-Lindau syndrome, neurofibromatosis type 1 (NF1), and tuberous sclerosis. ${ }^{14}$ A brief description of these syndromes has been presented in Table 2. One study showed that mutations associated with the MEN1 syndrome are much more common in children with insulinoma than in adults. ${ }^{15}$

VIPoma (VIP - vasoactive intestinal peptide), somatostatinoma and glucagonoma are extremely rare neuroendocrine neoplasms, which are practically not observed in children.

\section{Symptomatology}

In most cases, the diagnosis of NET of the gastrointestinal tract, due to its location in the appendix, is made accidentally during a histopathological examination, after an appendectomy was performed for another reason. Most frequently, they are small $(<2 \mathrm{~cm})$, hormonally inactive tumors without metastatic changes, with a very good prognosis and practically $100 \%$ survival. ${ }^{16}$ The young age of the disease development may be associated with a larger size of tumor and a higher risk of metastases.

Table 1. Classification of NET staging according to WHO of 2017

\begin{tabular}{|c|c|c|c|}
\hline NET G1 & NET G2 & NET G3 & NEC \\
\hline \multicolumn{2}{|c|}{ proliferative index $\mathrm{Ki}-67<20 \%$} & $\begin{array}{l}\text { proliferative index Ki-67>20\%; typically } \\
\qquad 21-55 \%\end{array}$ & $\begin{array}{l}\text { proliferative index } \mathrm{Ki}-67>20 \% \\
\text { typically }>55 \%\end{array}$ \\
\hline \multicolumn{3}{|c|}{ well-differentiated } & $\begin{array}{l}\text { poorly differentiated; divided into large- } \\
\text { and small-cell carcinomas }\end{array}$ \\
\hline of low malignancy & of medium malignancy & less aggressive than NEC & extremely aggressive \\
\hline
\end{tabular}

NET - neuroendocrine tumor; NEC - neuroendocrine carcinoma. 
Table 2. Hereditary syndromes associated with gastrointestinal and pancreatobiliary tract neuroendocrine tumors

\begin{tabular}{|c|c|c|c|c|}
\hline Parameter & MEN1 & $\begin{array}{l}\text { Von Hippel-Lindau } \\
\text { syndrome }\end{array}$ & NF1 & Tuberous sclerosis \\
\hline Mutation site & $11 q 13$ & $3 p 26-25$ & $17 q 11.2$ & $9 q 32$ \\
\hline $\begin{array}{l}\text { Inheritance } \\
\text { patterns }\end{array}$ & $\begin{array}{l}\text { autosomal dominant } \\
\text { inheritance }\end{array}$ & $\begin{array}{l}\text { autosomal dominant } \\
\text { inheritance }\end{array}$ & autosomal dominant inheritance & autosomal dominant inheritance \\
\hline $\begin{array}{l}\text { Clinical } \\
\text { characteristics }\end{array}$ & $\begin{array}{c}\text { primary } \\
\text { hyperparathyroidism; } \\
\text { neuroendocrine } \\
\text { neoplasms of pancreas, } \\
\text { digestive tract, bronchi } \\
\text { and thymus; pituitary } \\
\text { tumors }\end{array}$ & $\begin{array}{l}\text { increased risk of developing } \\
\text { various neoplasms includes: } \\
\text { cerebellar and spinal cord } \\
\text { hemangiomas, retinal } \\
\text { hemangiomas, clear cell } \\
\text { carcinoma of kidneys, } \\
\text { pheochromocytoma } \\
\text { of adrenal glands, } \\
\text { neuroendocrine tumors. } \\
\text { They are bilateral and } \\
\text { multifocal neoplasms, which } \\
\text { develop at a young age }\end{array}$ & $\begin{array}{c}\text { skin symptoms in the form } \\
\text { of 'coffee-milk' stains, freckled } \\
\text { spots in the armpit and } \\
\text { groin areas, subcutaneous } \\
\text { nodules with neuroma } \\
\text { or neurofibroma interweaving } \\
\text { pattern; furthermore, } \\
\text { increased risk of tumors such } \\
\text { as gliomas of the optic nerve, } \\
\text { meningiomas of the brain } \\
\text { and spinal cord, astrocytomas, } \\
\text { rhabdomyosarcomas, } \\
\text { pheochromocytoma and Wilms } \\
\text { tumors }\end{array}$ & $\begin{array}{l}\text { skin symptoms in the form } \\
\text { of colorless nevi on limbs and } \\
\text { trunk (may be present from } \\
\text { birth), the Pringle syndrome } \\
\text { demonstrated by red or pink } \\
\text { nodules (angiofibroma) appearing } \\
\text { on the face the age of 3, brown- } \\
\text { yellow and convex fibroma } \\
\text { of the forehead, subungual } \\
\text { and periungual fibromas and } \\
\text { scarring of the skin on the dorsal } \\
\text { part of the body; additionally, } \\
\text { the prevalence of the non-malignant } \\
\text { tumors in various organs }\end{array}$ \\
\hline
\end{tabular}

MEN1 - multiple endocrine neoplasia type 1; NF1 - neurofibromatosis type 1.

In a small proportion of patients, the symptoms may be identical to those of appendicitis (most sources indicate acute abdominal pain; rare chronic abdominal pain in the right abdominal quadrant has also been reported ${ }^{12}$ ). Cases of carcinoid syndrome in the course of NET located in the appendix have been described in the adult population. This syndrome develops when metastases to the liver are observed. Then, the substances secreted by the neuroendocrine neoplasms are no longer inactivated by the liver and are the cause of, i.a., redness of the face and neck, tachycardia, dizziness, excessive sweating, diarrhea and, infrequently, bronchospasm. However, no such symptoms have been observed in studies among children with a diagnosis of NET of the appendix..$^{17,18}$

Pancreatic NET are more frequently hormonally active than the gastrointestinal neuroendocrine tumor type. Hypoglycemia is the dominant symptom of insulinoma, a tumor which is derived from $\beta$-cells secreting insulin. The classic Whipple triad may be observed: symptoms occur during starvation and are accompanied by hypoglycemia; they disappear when carbohydrates are administered. In children, hypoglycemia usually manifests itself as behavioral disorders, convulsions or coma. These are non-characteristic ailments and may be observed in the course of many other diseases. Based on the available reports, the youngest age at diagnosis for pediatric insulinoma appears to be 3-4 years, thus this tumor is unlikely to be a cause of hypoglycemia in the youngest age group ( $<2$ years of age). In most cases, insulinoma is small in size, i.e., about $2 \mathrm{~cm}$, and is located mainly in the body and tail of the pancreas; approx. $1 \%$ of lesions are extrapancreatic. Ninety percent of all insulinomas are benign tumors. ${ }^{19}$

Gastrinoma is derived from G-cells that secrete gastrin. Typical symptoms for this NET include frequent, recurrent gastrointestinal ulcers manifested by chronic abdominal pain as well as symptoms suggesting reflux disease; less common are diarrhea and weight loss. Another symptom that may also be observed is anemia caused by abnormal iron absorption. All the aforementioned ailments are non-specific, which results in a diagnosis most frequently made with considerable delay, even up to 4-6 years after the occurrence of the first symptoms. ${ }^{20}$ Approximately $30 \%$ of tumors are located outside the pancreas: mainly in the so-called gastrinoma triangle including the duodenum, peri-pancreatic soft tissues and regional lymph nodes. Gastrinoma usually reaches a diameter of about $4 \mathrm{~cm}$ and, unlike insulinoma, only $40 \%$ of its tumors contain benign features. Multiple tumors and metastases may occur much more frequently even at very small primary focus sizes. Gastrinoma, similarly to the NET of pancreas that are hormonally inactive, shows a predilection for the pancreatic head.

VIPoma (derived from D1 cells of pancreas that secrete a vasoactive intestinal peptide) is most frequently manifested by diarrhea, hypocalcemia, dehydration, and acidosis. Somatostatinoma (derived from the D cells) causes cholelithiasis, diabetes and steatorrhea. Symptoms characteristic for glucagonoma (made up of the A-cells) include necrolytic erythema, glucose intolerance and weight loss.

As it is written in the introduction there are NETs which secrete hormones or hormonally inactive. Hormonally inactive pancreatic NETs are detected much later and in more advanced stage. This results from the lack of secretion of active substances giving clinical symptoms; thus, the neoplasm remains asymptomatic for a long time. The diagnosis is usually made when the tumor reaches a size that causes compression of adjacent structures. The symptoms most commonly include abdominal pain, weight loss, lack of appetite, and vomiting; less common are hepatitis or palpable tumor in the abdominal cavity. ${ }^{21}$ 


\section{Diagnostics}

Determining the level of chromogranin $\mathrm{A}(\mathrm{Cg} \mathrm{A})$ in the blood $^{22,23}$ is of essential significance in the laboratory diagnostics of NET. It is a sensitive but not a very specific marker. False positive results of the $\mathrm{Cg}$ A assay are observed when taking proton pump inhibitors (PPIs) in atrophic gastritis or renal failure, and after a meal or after physical activity which took place $2-4 \mathrm{~h}$ prior to blood sampling. The increased Cg A levels can also be caused by other neoplasms (small-cell lung cancer, medullary thyroid cancer, pheochromocytoma, liver cancer, or adenocarcinoma of the pancreas). The highest $\mathrm{Cg}$ A values were observed in NET of the small intestine, gastrinoma and glucagon, as well as in patients with carcinoid syndrome. For insulinoma, $\mathrm{Cg}$ A levels were often within normal limits, so the possibility of determining the level of chromogranin B should be considered for the diagnosis of insulinoma. A normal level of chromogranin A does not exclude the diagnosis of NET. There are several methods of determining $\mathrm{Cg} \mathrm{A}$, so it is important for the subsequent assessment of the response to treatment that determination of $\mathrm{Cg} \mathrm{A}$ is performed using the same method. ${ }^{22}$

Following the guidelines of the Polish Society of Endocrinology, the gold standard of diagnostic management for insulinoma is a 72-hour hunger test (some sources give a sufficient time of $48 \mathrm{~h}$, which may be helpful in diagnosing the youngest patients). The test must be carried out in a hospital environment. Initially, the blood glucose level is determined in series, until it reaches a value $\leq 2.2 \mathrm{mmol} / \mathrm{L}$; then, the $\mathrm{C}$-peptide, pro-insulin and insulin levels in the blood are determined. The diagnosis of insulinoma is based on the following criteria: documented glycemia $\leq 2.2 \mathrm{mmol} / \mathrm{L}(\leq 40 \mathrm{mg} / \mathrm{dL})$ with concomitant inadequate insulin concentration $\geq 6 \mathrm{mU} / \mathrm{L}(\geq 36 \mathrm{pmol} / \mathrm{L})$, C-peptide concentration $\geq 200 \mathrm{pmol} / \mathrm{L}$, and pro-insulin concentration $\geq 5 \mathrm{pmol} / \mathrm{L} .{ }^{22,23}$

If gastrinoma is suspected, the laboratory diagnosis includes: determination of the fasting serum gastrin concentration and evaluation of the gastrin concentration after being stimulated with secretin ( $2 \mathrm{~J} / \mathrm{kg}$ body weight intravenously (i.v.)) or calcium gluconate in doubtful cases. The increased blood gastrin level, over 10 times higher than normal at gastric $\mathrm{pH}<2$, is typical, but does not enable a diagnosis because other causes of hypergastrinemia may also be accounted for, i.a., the use of PPIs, Heliobacter pylori infection, atrophic gastritis, pyloric stenosis, or renal failure; $\mathrm{pH}>3$ is very likely to exclude the existence of gastrinoma. The secretin stimulation test is performed on an empty stomach; secretin is administered i.v., followed by the determination of the baseline level $(15 \mathrm{~min}$ and $1 \mathrm{~min}$ before secretin is administered) and of the gastrin levels in series within $30 \mathrm{~min}(2,5,10,15,20$, and $30 \mathrm{~min}$ after secretin has been administered). Diagnosis is made when a value of $120 \mathrm{pg} / \mathrm{mL}$ above the baseline is obtained at any measuring point. ${ }^{22,23}$
It is advisable to carry out the appropriate test in patients under 20 years of age in connection with the significantly higher prevalence of MEN1 among people of that age, regarding a diagnosis of insulinoma and gastrinoma. Monitoring of such patients with endoscopic ultrasound (EUS) should also be considered, since it facilitates early detection of small pancreatic tumors, particularly the hormonally inactive NET of the pancreas, ${ }^{23}$ which do not give early symptoms. This is followed by diagnostic imaging, which frequently includes not only anatomical but also functional imaging. The literature provides a limited amount of information on the imaging of neuroendocrine neoplasms in children. Most of the recommendations follow the practices accepted for adult patients. Computed tomography (CT) is highly sensitive in detecting both the primary focus and potential metastases. ${ }^{24}$ However, it is associated with exposure of the youngest patients to radiation, so the test protocol should be selected in such manner to minimize the radiation to the lowest possible dose while maintaining the diagnostic values of the test. Enteroclysis or enterography, which increase the sensitivity of CT examination to $100 \%$, are performed to provide a more accurate imaging of the small intestine. ${ }^{25}$ Magnetic resonance imaging is characterized by higher sensitivity in detecting liver metastases ${ }^{26}$ than $\mathrm{CT}$, as well as by a very good detection of pancreatic tumors and lymph node metastasis. Endoscopic ultrasound is a good method of imaging pancreatic tumors located mainly in the head of the pancreas and duodenum..$^{27}$ Gastroscopy should be the first imaging examination in patients with a suspected cancer located in the upper gastrointestinal tract. Tissue samples may be collected when both the EUS and gastroscopy are being performed.

Functional imaging consists in the administration of somatostatin analogues labeled with radioisotope (somatostatin receptor imaging - SRI), showing affinity to glycoprotein receptors which are found in most neuroendocrine neoplasms. Currently, the most commonly used techniques include labeling with technetium (scintigraphy) or with positron markers $\left({ }^{68} \mathrm{Ga}\right.$; positron emission tomography (PET)) to locate the primary focus and metastases. Isotope diagnostics, using the radioactive tracer - fludeoxyglucose labeled fludeoxyglucose ${ }^{18}$ (FDG), is used to evaluate the degree of NET malignancy. This examination produces negative results in a large number of patients with NET, but the accumulation of ${ }^{18} \mathrm{FDG}$ in neoplastic lesions indicates a high degree of cancer malignancy, which enables selection of an appropriate treatment line and an evaluation of prognosis. Location of the primary focus and the evaluation of the disease severity are the indications for SRI; it may also be used to monitor treatment.

Selection of the type of imaging examination should depend on the available technologies, applied research protocols and the staff experience in a given unit. Histopathological diagnosis of the gastrointestinal and pancreatic NET includes: histological type assessment according 
to the WHO classification of $2017,{ }^{3}$ immune-histochemical evaluation of the expression of $\mathrm{CgA}$ and synaptophysin neuroendocrine markers, the proliferative activity of Ki-67/MIB1, and the histopathological level evaluation according to European Neuroendocrine Tumor Society (ENETS) and American Joint Committee on Cancer (AJCC) of 2017, as well as an evaluation of surgical margins.

\section{Management}

Unlike adults, in whom the treatment of NET located in the appendix depends on the size of the tumor, local infiltration and lymph node metastasis (patients with tumor $>2 \mathrm{~cm}$, infiltration to the adjacent structures or the lymph node metastasis are qualified for right hemicolectomy), it seems that in children, appendectomy is a sufficient treatment, regardless of the size of the tumor, its location in the appendix, lymph node metastasis, or intestine mesentery. ${ }^{28,29}$ However, some sources recommend an approach analogous to the recommendations administered for adults. ${ }^{30}$

Treatment of NET located elsewhere mainly involves surgical management. The aim is to achieve a complete resection of the tumor, which guarantees full recovery of the patient. In children, NET are usually in the form of a small tumor, well-differentiated and non-infiltrating to adjacent structures, which usually allows for complete resection. No additional treatment of hormonally inactive NET is required in most cases.

Additional preoperative medication management is required in patients with insulinoma. An i.v. infusion of glucose is used, which is usually insufficient to maintain a normal level of glycemia, and a dose of 5-10 mg/ $\mathrm{kg} /$ day of diazoxide is administered. ${ }^{31}$

Preoperative medication management is also required in patients with gastrinoma to inhibit gastric hypersecretion and avoid severe complications. Proton pump inhibitors used in high doses are the first-line drugs. The limited amount of data provided by the literature indicates that the metabolism of PPIs may be reduced in newborns, whereas in children between 1 and 9 years of age, it may be increased, which is worth noting when determining the dosage of these drugs. The aim of the treatment is to achieve a basal acid output (BAO) of less than $10 \mathrm{mEq} / \mathrm{h} .{ }^{32}$ The appropriate BAO in healthy people is $5 \mathrm{mEq} / \mathrm{h}$.

\section{Post-treatment control}

Since NET occur in the pediatric population very rarely, there are no uniform recommendations for the post-treatment follow-up of NET in the youngest patients. Recommendations of the Polish Society of Endocrinology, created for adults, are justified to be applied in this respect:
- patients with benign, well-differentiated NET $<1 \mathrm{~cm}$ in diameter, with a total tumor resection (R0), do not require further monitoring in most cases;

- NET patients with histological type G1 should be monitored every 6-12 months;

- NET patients with histological type G2 should be monitored every 3-6 months;

- NET patients with histological type G3 should be monitored every 3 months.

Post-treatment monitoring includes: CgA level, 5-hydroxyindoleacetic acid (5-HIAA) level (in selected cases), three-phase CT, and somatostatin-receptor-based imaging.

It is also very important to have a genetic consultation for each newly diagnosed NET in a child. The aim is both to diagnose rare genetic syndromes that predispose to the development of NET, and thus increased monitoring to enable early detection of further cancers, and to provide genetic counseling for the whole family.

\section{Summary}

It is important to know the epidemiology and symptomatology of neuroendocrine neoplasms in this age group despite the fact that the majority of physicians dealing with the youngest patients will never encounter a case of NET in a child or will only encounter them a few times during their entire professional career. This will facilitate an early diagnosis in case of symptoms that may suggest neuroendocrine cancer. It appears necessary to create harmonized recommendations regarding the diagnosis, treatment and post-treatment follow-up for pediatric patients.

\section{ORCID iDs}

Andrzej Stawarski (1) https://orcid.org/0000-0002-9486-1682

Paweł Maleika (1) https://orcid.org/0000-0003-1408-6653

\section{References}

1. Johnson PRV. Gastroenteropancreatic neuroendocrine (carcinoid) tumors in children. Semin Pediatr Surg. 2014;23(2):91-95. doi:10.1053/j. sempedsurg.2014.03.007

2. Kloppel G. Classification and pathology of gastroenteropancreatic neuroendocrine neoplasms. Endocr Relat Cancer. 2011;18(Suppl 1): S1-S16. doi:10.1530/erc-11-0013

3. WHO Classification of Tumours of the Digestive System. IARC: Lyon 2017 (in press). http://publiczno-prywatni/554.

4. Yao JC, Hassan M, Phan A. One hundred years after 'carcinoid': Epidemiology of and prognostic factors for neuroendocrine tumors in 35,825 cases in the United States. J Clin Oncol. 2008;26(18):30633072. doi:10.1200/JCO.2007.15.4377

5. Parkes S, Muir K, Al Sheyyab M. Carcinoid tumors of the appendix in children 1957-1986: Incidence, treatment and outcome. Br J Surg. 1993;80(4):502-504. doi:10.1002/bjs.1800800433

6. Navalkele P, O'Dorisio M, O'Dorisio TM. Neuroendocrine tumors in children and young adults: Incidence, survival, and prevalence in the United States. Pancreas. 2010;39(2):278. doi:10.1097/01.mpa. 0000363933.98540.e2

7. Diets IJ, Nagtegaal ID, Loeffen J, et al. Childhood neuroendocrine tumours: A descriptive study revealing clues for genetic predisposition. Br J Cancer. 2016;116(2):163-168. doi:10.1038/bjc.2016.408

8. Modlin IM, Lye KD, Kidd M. A 5-decade analysis of 13,715 carcinoid tumors. Cancer. 2003;97(4):934-959. doi:10.1002/cncr.11105 
9. Corpron CA, Black CT, Herzog CE. A half century of experience with carcinoid tumors in children. Am J Surg Pathol. 1995;170(6):606-608. doi:10.1016/S0002-9610(99)80025-7

10. Spunt SL, Pratt CB, Rao BN, et al. Childhood carcinoid tumors: The St Jude Children's Research Hospital experience. J Pediatr Surg. 2000; 35(9):1282-1286. doi:10.1053/jpsu.2000.9297

11. Prommegger $R$, Obrist $P$, Ensinger $C$. Retrospective evaluation of carcinoid tumors of the appendix in children. World J Surg. 2002;26(12): 1489-1492. doi:10.1007/s00268-002-6440-3

12. Dall'Igna P, Ferrari A, Luzzatto $C$, et al. Carcinoid tumor of the appendix in childhood: The experience of two Italian institutions. J Pediatr Gastroenterol Nutr. 2005;40(2):216-219. doi:10.1097/00005176200502000-00025

13. Service FJ, McMahon MM, O'Brien PC. Functioning insulinoma: Incidence, recurrence, and long-term survival of patients. A 60-year study. Mayo Clin Proc. 1991;66(7):711-719. doi:10.1016/S00256196(12)62083-7

14. Ehehalt F, Saeger HD, Schmidt CM. Neuroendocrine tumors of the pancreas. Oncologist. 2009;14(5):456-467. doi:10.1634/theoncologist.2008-0259

15. Bhatti TR, Ganapathy K, Huppmann AR, et al. Histologic and molecular profile of pediatric insulinomas: Evidence of a paternal parent-of-origin effect. J Clin Endocrinol Metab. 2016;101(3):914-922. doi:10.1210/jc. 2015-2914

16. Kulkarni KP, Sergi C. Appendix carcinoids in childhood: Long-term experience at a single institution in Western Canada and systematic review. Pediatr Int. 2013;55(2):157-162. doi:10.1111/ped.12047

17. Moertel CL, Weiland LH, Telander RL. Carcinoid tumor of the appendix in the first two decades of life. J Pediatr Surg. 1990;25(10): 1073-1075. doi:10.1016/0022-3468(90)90221-T

18. Ryden SE, Drake RM, Franciosi RA. Carcinoid tumors of the appendix in children. Cancer. 1975;36(4):1538-1542. doi:10.1002/1097-0142 (197510)36:4<1538::AID-CNCR2820360448>3.0.CO;2-C

19. Solcia E, Capella C, Klöppel G. Atlas of Tumor Pathology: Tumors of the Pancreas. Washington: DC: Armed Forces Institute of Pathology; 1997.

20. Citak EC, Taşkinlar H, Arpaci RB, et al. Primary lymph node gastrinoma: A rare cause of abdominal pain in childhood. J Pediatr Hemat Oncol. 2013;35(5):394-398. doi:10.1097/MPH.0b013e318298de7e

21. Falconi M, Bartsch DK, Eriksson B, et al. Barcelona Consensus Conference participants. ENETS Consensus Guidelines for the management of patients with digestive neuroendocrine neoplasms of the digestive system: Well-differentiated pancreatic non-functioning tumors. Neuroendocrinology. 2012;95(2):120-134. doi:10.1159/000335587
22. Kos-Kudła B, Blicharz-Dorniak J, Strzelczyk J, et al. Diagnostic and therapeutic guidelines for gastro-entero-pancreatic neuroendocrine neoplasms (recommended by the Polish Network of Neuroendocrine Tumours). Endokrynol Pol. 2017;68(2):79-110. doi:10.5603/ EP.2017.0015

23. Kos-Kudła B, Hubalewska-Dydejczyk A, Kuśnierz K, et al. Pancreatic endocrine tumors: Management guidelines (recommended by the Polish Network of Neuroendocrine Tumors). Endokrynol Pol. 2017; 68(2):169-197. doi:10.5603/EP.2017.2017

24. Kumbasar B, Kamel IR, Tekes A. Imaging of neuroendocrine tumors: Accuracy of helical CT versus SRS. Abdom Imaging. 2004;29(6): 696-702. doi:10.1007/s00261-003-0162-3

25. Kamaoui I, De-Luca V, Ficarelli S. Value of CT enteroclysis in suspected small-bowel carcinoid tumors. AJR Am J Roentgenol. 2010;194(3): 629-633. doi:10.2214/AJR.09.2760

26. Khanna G, O'Dorisio SM, Menda Y. Gastroenteropancreatic neuroendocrine tumors in children and young adults. Pediatr Radiol. 2008; 38(3):251-259. doi:10.1007/s00247-007-0564-4

27. Delle Fave G, O'Toole D, Sundin A, et al. Vienna Consensus Conference participants. ENETS Consensus Guidelines Update for Gastroduodenal Neuroendocrine Neoplasms. Neuroendocrinology. 2016;103(2): 119-124. doi:10.1159/000443168

28. Njere I, Smith LL, Thurairasa D, et al. Systematic review and metaanalysis of appendiceal carcinoid tumors in children. Pediatr Blood Cancer. 2018;65(8):e27069. doi:10.1002/pbc.27069

29. de Lambert G, Lardy H, Martelli H. Surgical management of neuroendocrine tumors of the appendix in children and adolescents: A retrospective French multicenter study of 114 cases. Pediatr Blood Cancer. 2016;63(4):598-603. doi:10.1002/pbc.25823

30. Boudreaux JP, Klimstra DS, Hassan MM, et al. The NANETS consensus guideline for the diagnosis and management of neuroendocrine tumors: Well-differentiated neuroendocrine tumors of the jejunum, ileum, appendix, and cecum. Pancreas. 2010;39(6):753-766. doi:10.1097/MPA.0b013e3181ebb2a5

31. Hoe FM, Thornton PS, Wanner LA. Clinical features and insulin regulation in infants with a syndrome of prolonged neonatal hyperinsulinism. J Pediatr. 2006;148(2):207-212. doi:10.1016/j.jpeds.2005.10.002

32. Patton TJ. Pediatric Zollinger-Ellison Syndrome. Medscape. https:// emedicine.medscape.com/article/932553-overview. Updated October 6, 2017. Accessed February 11, 2019. 